Article

\title{
The Novel Aminomethylcycline Omadacycline Has High Specificity for the Primary Tetracycline-Binding Site on the Bacterial Ribosome
}

\author{
Corina G. Heidrich ${ }^{1}$, Sanya Mitova ${ }^{1}$, Andreas Schedlbauer ${ }^{2}$, Sean R. Connell ${ }^{2,3}$, \\ Paola Fucini ${ }^{2,3}$, Judith N. Steenbergen ${ }^{4}$ and Christian Berens ${ }^{1,5, *}$ \\ 1 Microbiology, Department of Biology, Friedrich-Alexander-Universität Erlangen-Nürnberg, \\ 91058 Erlangen, Germany; corina.heidrich@gmail.com (C.G.H.); sanya.mitova@hotmail.de (S.M.) \\ 2 Structural Biology Unit, CIC bioGUNE, 48160 Derio, Bizkaia, Spain; aschedlbauer@cicbiogune.es (A.S.); \\ sean.connell@gmail.com (S.R.C.); pfucini@gmail.com (P.F.) \\ 3 IKERBASQUE, Basque Foundation for Science, 48013 Bilbao, Spain \\ 4 Paratek Pharmaceuticals Inc., King of Prussia, PA 19406, USA; judith.steenbergen@paratekpharma.com \\ 5 Institute of Molecular Pathogenesis, Friedrich-Loeffler-Institut, 07743 Jena, Germany \\ * Correspondence: christian.berens@fli.de; Tel.: +49-3641-804-2500
}

Academic Editor: Claudio O. Gualerzi

Received: 27 March 2016; Accepted: 12 September 2016; Published: 22 September 2016

\begin{abstract}
Omadacycline is an aminomethylcycline antibiotic with potent activity against many Gram-positive and Gram-negative pathogens, including strains carrying the major efflux and ribosome protection resistance determinants. This makes it a promising candidate for therapy of severe infectious diseases. Omadacycline inhibits bacterial protein biosynthesis and competes with tetracycline for binding to the ribosome. Its interactions with the $70 \mathrm{~S}$ ribosome were, therefore, analyzed in great detail and compared with tigecycline and tetracycline. All three antibiotics are inhibited by mutations in the 16S rRNA that mediate resistance to tetracycline in Brachyspira hyodysenteriae, Helicobacter pylori, Mycoplasma hominis, and Propionibacterium acnes. Chemical probing with dimethyl sulfate and Fenton cleavage with iron(II)-complexes of the tetracycline derivatives revealed that each antibiotic interacts in an idiosyncratic manner with the ribosome. X-ray crystallography had previously revealed one primary binding site for tetracycline on the ribosome and up to five secondary sites. All tetracyclines analyzed here interact with the primary site and tetracycline also with two secondary sites. In addition, each derivative displays a unique set of non-specific interactions with the 16S rRNA.
\end{abstract}

Keywords: tetracycline; tigecycline; omadacycline; tetracycline resistance; antibiotics; antibiotic resistance; chemical probing; ribosome structure

\section{Introduction}

Typical tetracyclines [1], like tetracycline (TET) or tigecycline (TGC), inhibit bacterial protein biosynthesis by binding to the $30 \mathrm{~S}$ ribosomal subunit [2-5] and preventing stable accommodation of the EF-Tu-GTP-aa-tRNA complex at the ribosomal A-site [4,6]. Tetracyclines have broad-spectrum activity against many infectious disease agents, including Gram-negative and Gram-positive bacteria, intracellular pathogens, and even protozoan parasites (summarized in reference [7]). This, their low cost of production [8], and the absence of major adverse side-effects have led to their widespread application-not only for treating human and animal infections, but also as prophylactic or growth-promoting agents in animal feed [9]. Unfortunately, the extensive use of tetracyclines has severely limited their efficacy as antibiotics due to the concomitant emergence and spread of microbial resistance. Roughly 50 different determinants currently mediate resistance to the older clinically 
established tetracyclines. They have been grouped into two major mechanisms, drug efflux and ribosome protection, and two minor mechanisms, modification of the ribosomal target (16S rRNA mutations) and enzymatic inactivation [8-10].

The increasing prevalence of tetracycline-resistant bacteria has triggered the development of new tetracycline derivatives, which are modified at positions C-7 and C-9 of the tetracycline D-ring (Figure 1A) and are highly active against organisms carrying the major resistance determinants.

A

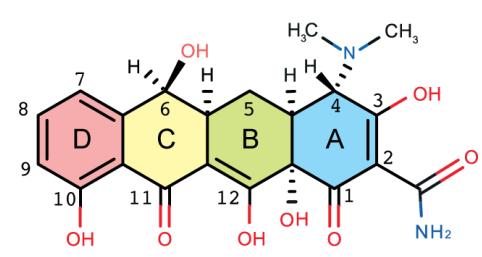

Tetracycline<smiles>CN(C)c1cc(NC(=O)CNC(C)(C)C)c(O)c2c1C[C@H]1C[C@@H]3C(=O)C(=O)C(C(N)=O)=C(O)[C@]3(N(C)C)C(O)=C1C2=O</smiles>

Tigecycline

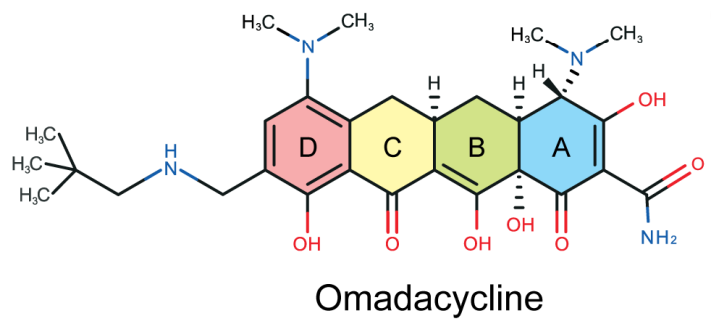

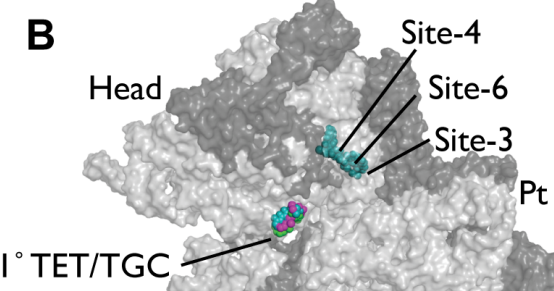

Body

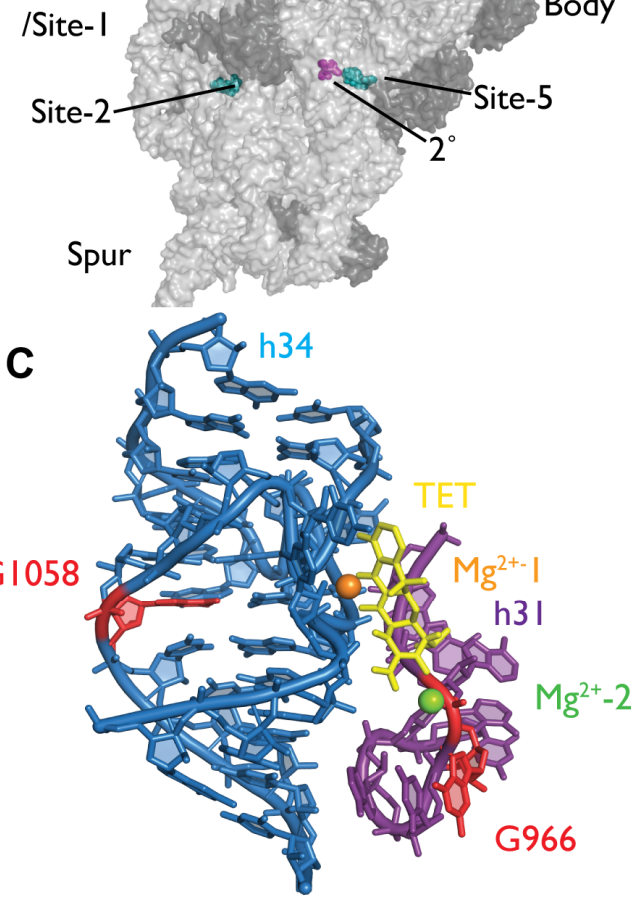

Figure 1. Tetracycline, tigecycline and omadacycline, the tetracycline binding sites and proximity of tetracycline rRNA resistance mutations to the primary binding site. (A) The chemical structures of tetracycline, tigecycline, and omadacycline drawn schematically with their common backbone ring structures (rings A-D) colored distinctly. Carbon atom assignments for the 4-ring backbone are indicated on tetracycline; (B) The primary and secondary tetracycline binding sites as observed in X-ray crystallography studies [2-4] are shown on the structure of the 30S ribosomal subunit (rRNA, light grey surface; ribosomal-proteins, dark grey surface). The primary $\left(1^{\circ}\right)$ and secondary $\left(2^{\circ}\right)$ TET binding sites observed by Brodersen et al. are colored pink, the primary $\left(1^{\circ}\right)$ site described by Jenner et al. is green but largely obscured underneath TET, and the TET binding sites 1-6 observed by Pioletti et al. are colored blue and labeled distinctly. The head, spur, platform (Pt) and body $30 \mathrm{~S}$ subunit landmarks are labeled; (C) The primary tetracycline binding site according to Jenner et al. [4] is illustrated showing the two rRNA bases, G1058 and G966, whose mutation results in tetracycline resistance.

The first representative of this third generation to have been approved by the FDA is tigecycline, a glycylcycline (Figure 1A) [11]. Another representative in clinical development is the semi-synthetic 9-aminomethylcycline omadacycline (Figure 1A) [12]. Both display potent activity against Gram-positive and Gram-negative bacteria, including strains carrying efflux and ribosome protection resistance determinants [13,14]; however, it has been shown that TGC remains susceptible 
to the minor tetracycline resistance mechanisms $[15,16]$. These new tetracycline derivatives inhibit bacterial protein biosynthesis and compete with TET for binding to the ribosome [4,13,17]. The binding of TET and TGC to the ribosome has been characterized using X-ray crystallography [2-5] showing that both bind to overlapping sites in the ribosomal A-site (primary $\left(1^{\circ}\right) /$ site-1; Figure $1 \mathrm{~B}$ ) [4]. Interestingly TET, but not TGC, was shown in two studies $[2,3]$ to bind to several secondary sites (labeled secondary $\left(2^{\circ}\right)$ and sites 2-6; Figure $1 B$ ) that are consistent with previous biochemical investigations (reviewed in [18]).

The structural basis for the interaction of omadacycline (OMC) with the ribosome is uncharacterized. OMC is currently in clinical development for treatment of acute bacterial skin and skin structure infections and community-acquired bacterial pneumonia. It also compared favorably with linezolid in a randomized, investigator-blind, multicenter phase 2 trial for complicated skin and skin structure infections [19]. Due to its activity profile, the oral availability, and because OMC appears to be well-tolerated by patients, this aminomethylcycline has the potential to become an effective agent for treatment of serious infections. A thorough understanding of how OMC acts mechanistically will help to better evaluate its strengths as a therapeutic agent, as well as its limitations. OMC competes with TET for binding to the ribosome [4,13], but it is not clear if this competition occurs at the primary site [2-4] or at one or more of the secondary sites [2,3] (Figure 1B). Genetic analysis with 16S rRNA tetracycline-resistance mutations [20-24] and chemical probing [15,25] can identify and compare the TET, TGC, and OMC binding sites on the 16S rRNA. We, therefore, used these methods for the identification and characterization of OMC binding sites on Escherichia coli $70 \mathrm{~S}$ ribosomes and compared them with binding sites for TET and TGC.

\section{Results}

\subsection{Omadacycline Is Susceptible to $16 S$ rRNA Mutations Conferring TET Resistance}

Although it is known that OMC competes with TET for binding to the ribosome [13], it is unclear if this competition occurs at the primary and/or the many secondary tetracycline binding sites [3] (Figure 1B). To genetically address the specificity of the ribosome-OMC interaction, we determined the susceptibility of strains harboring tetracycline-resistance mutations that surround the primary tetracycline-binding site (Figure 1C). These $16 \mathrm{~S}$ rRNA mutations include (1) the $1058 \mathrm{G} \rightarrow \mathrm{C}$ (helix 34 , h34) exchange, found in Propionibacterium acnes and Brachyspira hyodysenteriae [20,22], and (2) the 966 $\mathrm{G} \rightarrow \mathrm{U}$ (helix 31, h31) transversion identified in Helicobacter pylori [21] (Figure 1C). These mutations were introduced into E. coli TA527 [26], a strain that lacks all seven chromosomal rRNA operons, but instead carries a single plasmid-borne rRNA operon [27]; this allows 16S rRNA resistance mutations to be studied without any interfering wild type background. As summarized in Table 1, we determined the minimal inhibitory concentrations (MICs) of the E. coli quality control strain ATCC-25922, as well as E. coli TA527, carrying either wild-type (pKK3535) or mutant (pKK966U and pKK1058C) 16S rRNA genes, for the antibiotics TET, TGC, and OMC.

Table 1. Minimal inhibitory concentrations of TET, TGC, and OMC for E. coli strains with tetracycline-sensitive and tetracycline-resistant ribosomes.

\begin{tabular}{cccccc}
\hline \multirow{2}{*}{ Test Compound } & \multirow{2}{*}{ MIC Parameter } & \multicolumn{4}{c}{ Value $(\mu \mathrm{g} / \mathbf{m L})$ against Each Bacterial Strain } \\
\cline { 3 - 6 } & & ATCC-25922 & TA527 (wt) & TA527/1058C & TA527/966U \\
\hline Tetracycline & MIC (fold increase) & 1 & 2 & $8(4 \times)$ & $16(8 \times)$ \\
Tigecycline & MIC (fold increase) & 0.06 & 0.25 & $1(4 \times)$ & $1(4 \times)$ \\
Omadacycline & MIC (fold increase) & nd & 2 & $8(4 \times)$ & $16(8 \times)$ \\
\hline
\end{tabular}

The MIC values were determined by the agar dilution method according to CLSI standards, except that the plates were incubated for $40 \mathrm{~h}$. The permitted MIC range of the quality control strain 
ATCC-25922 is $0.5-2 \mu \mathrm{g} / \mathrm{mL}$ for tetracycline and $0.03-0.25$ for tigecycline. Fold-increases in MIC values in strains with tetracycline-resistant ribosomes are given in parentheses; nd: not determined.

When compared to E. coli TA527 carrying a wild-type rRNA operon, both mutants showed a 4- to 8-fold increase in their MIC, indicating that all three drugs (TET, TGC, and OMC) are susceptible to 16S rRNA resistance mutations. As these mutations cluster around the primary tetracycline-binding site (Figure 1C), it is highly likely that OMC binds to this site similar to TET and TGC.

\subsection{Chemical Probing Indicates That OMC Binds Specifically to the Primary TET Binding Site}

To further establish that OMC binds to the bacterial ribosome at a site corresponding to the primary tetracycline binding site, we employed chemical probing (dimethyl sulfate (DMS) and $\mathrm{Fe}^{2+}$-mediated Fenton cleavage) to map the interaction of OMC on the $16 \mathrm{~S}$ rRNA. In the first set of experiments, DMS modification of the 16S rRNA was carried out in the presence of TET, TGC, and OMC to test if the three drugs show overlapping modification patterns. Empty $70 S$ ribosomes $(0.5-0.6 \mu \mathrm{M})$ from E. coli CAN/20-E12 were treated with DMS in the presence of TET, TGC or OMC at concentrations ranging from 0.3 to $300 \mu \mathrm{M}$.

The C1054 (h34) enhancement ( 1.5-fold), characteristic of tetracycline binding to the primary binding site, was observed for all compounds-even at the lowest concentration tested $(0.3 \mu \mathrm{M}$; Figure 2A). In contrast, the protection of A892 from DMS methylation, which is indicative of binding to the secondary site near h27 of the $16 \mathrm{~S}$ rRNA, was only detected with TET, and not with TGC or OMC (Figure 2B). Specifically, quantification showed that the intensity of the signal corresponding to A892 steadily decreased at TET concentrations from $0.3 \mu \mathrm{M}$ up to $300 \mu \mathrm{M}$ yielding a 6-fold reduction, while over a similar 1000-fold difference in concentration, TGC and OMC did not affect signal intensity (Figure 2B). We also observed a signal enhancement in the presence of the antibiotics. This was not seen with the previous protocol [15]. Since TET displayed a concentration-dependent decrease in signal intensity at A892, this initial enhancement might be caused indirectly by a structural change due to antibiotic binding to another site which then affects A892 exposure to DMS.

In a second series of experiments, the interaction of OMC with the 16S rRNA was characterized and compared to that of TET and TGC using $\mathrm{Fe}^{2+}$-mediated Fenton cleavage. TET generally chelates a $\mathrm{Mg}^{2+}$ ion using the polar face of rings $\mathrm{B}$ and $\mathrm{C}$ and this $\mathrm{Mg}^{2+}$ ion is an important component of the TET binding pocket (Figure 1; $\mathrm{Mg}^{2+}-1$ ) [2-5]. In this approach the $\mathrm{Mg}^{2+}$ ion is substituted with an $\mathrm{Fe}^{2+}$ ion $\left(\mathrm{Fe}^{2+}\right.$ has a 30-500-fold higher affinity to tetracycline than $\mathrm{Mg}^{2+}$ [28]) such that when the TET-Fe ${ }^{2+}$ chelate binds to the ribosome it can be used to generate $\mathrm{Fe}^{2+}$-dependent hydroxyl radicals (See Material and Methods) that cleave the rRNA in the local environment. Previously, this approach successfully mapped TET binding sites on the Tet repressor protein TetR [29] and the TET efflux protein TetA [30], as well as TET and TGC binding sites on the ribosome [15]. It is important to note that the $\mathrm{Fe}^{2+}$ and $\mathrm{Mg}^{2+}$ in the TET-chelate complex are considered isostructural [31] as $\mathrm{Fe}^{2+}$ can substitute for $\mathrm{Mg}^{2+}$ to induce the Tet repressor [29]. Using this approach, we probed empty ribosomes from E. coli CAN/20-E12 $(2 \mu \mathrm{M})$ in the presence of TET, TGC, and OMC (1 to $125 \mu \mathrm{M})$ (Figure 3 and Figure S1).

Similar to the DMS probing results, all three drugs showed overlapping cleavage patterns at the primary tetracycline binding site, whereas only TET mapped to the secondary binding site near $\mathrm{h} 27$ of the 16S RNA (Figure 3). Specific quantification of the cleavage sites seen in Figure 3 show that all three drugs enhanced the cleavage of U965 (h31), C1195 (h34), and A1197 (h34), while G1053 (h34) and C1054 (h34) were protected from cleavage. In contrast, only TET was observed to enhance cleavage of a residue close to a secondary binding site (G894, h27; Figure 3D). To validate that $\mathrm{Fe}^{2+}$ was interacting with a similar site as $\mathrm{Mg}^{2+}$, we performed a $\mathrm{Mg}^{2+}$ competition experiment and showed that $\mathrm{Fe}^{2+}$ dependent cleavage was reduced at all specific and non-specific cleavage sites identified for TET, TGC, and OMC, reaching intensities close to the background level (Figure S2). It is interesting to note that we also observed sixteen additional cleavage sites, but only at high antibiotic concentrations $(\geq 25 \mu \mathrm{M}$; Figure S3). This is the first time that such frequent and idiosyncratic cleavage sites have been observed for tetracycline derivatives. They likely represent non-specific sites given that tetracyclines are known 
to bind non-specifically to RNA [32] particularly at concentrations above $40 \mu \mathrm{M}$ [33]. Nevertheless, many map to sites (summarized in Table 2) that have been published either as tetracycline-affected (G242-G247, A279; G682/G683, U692/G693, A702/G703; G1166-A1169) or as interaction sites of molecules that are affected by tetracycline binding, like tRNA (U531/A532; G682/G683, U692/G693, A702/G703; U788/U789; G925-C930) or the S7 protein (U957/A958, A1257, G1260; A1360).

\section{A C1054}

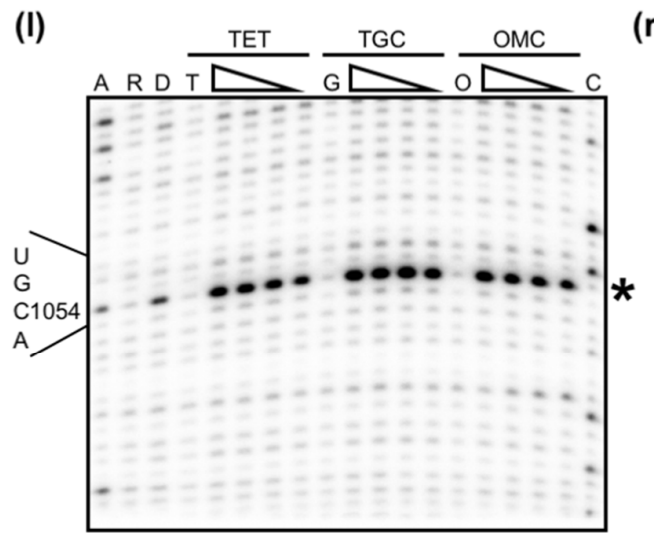

(r)

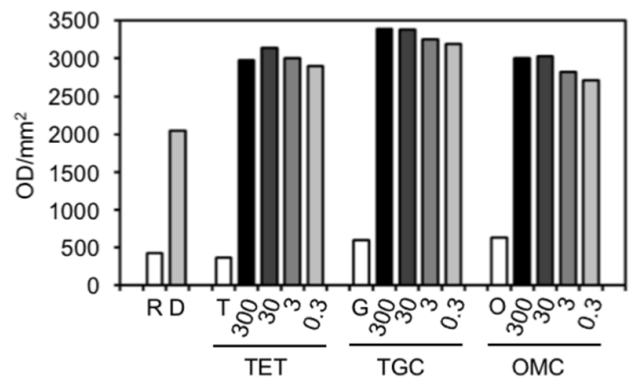

\section{B A892}

(I)

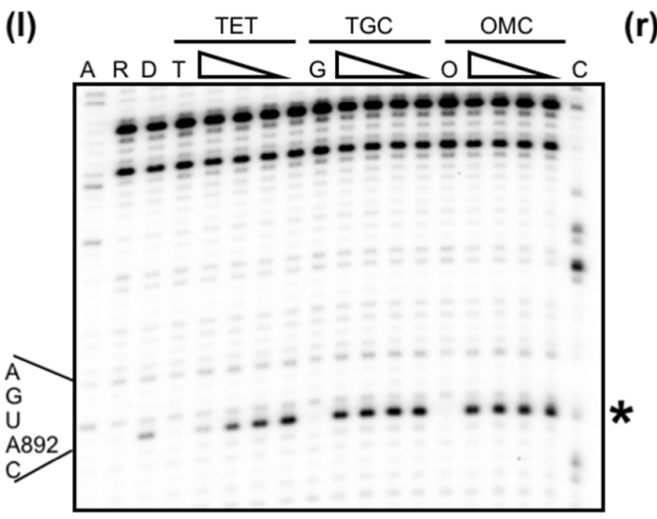

(r)

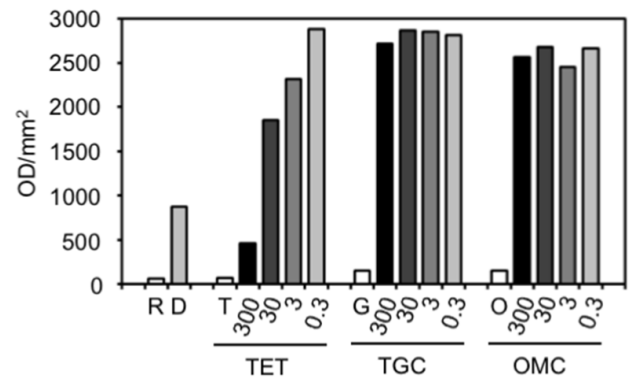

Figure 2. TET, TGC, and OMC affect DMS modification of bases in the16S rRNA. Empty E. coli $70 S$ ribosomes $(0.5-0.6 \mu \mathrm{M})$ were incubated with varying amounts of TET, TGC or OMC and methylated with DMS. Modification of nucleotides (A) C1054 and (B) A892 was detected by primer extension and analyzed by electrophoresis on denaturing $6 \%$ polyacrylamide gels, sections of which are shown in the panels (l) left of the plots ( $\mathrm{r}$ ) showing their respective quantification. The dideoxy sequencing lanes are indicated with A and C; the unmodified RNA with R; the unmodified rRNA in the presence of the antibiotics TET, TGC or OMC with T, G, and O respectively; the DMS-modified RNA in the absence of antibiotics with D; and the DMS modified RNA in the presence of antibiotic is indicated with wedges under the TET, TGC, OMC headers where the wedge represents the presence of antibiotics at $300,30,3$, and $0.3 \mu \mathrm{M}$. The extent of DMS modification of the rRNA in the presence of increasing amounts of antibiotic was quantitated in a phosphorimager and is shown below the gel sections with a comparison to the control DMS-modified RNA in the absence of antibiotics (lanes designated as " $\mathrm{D}$ "). Quantification was adjusted for loading differences by normalization with regions unaffected by TET, TGC or OMC. 

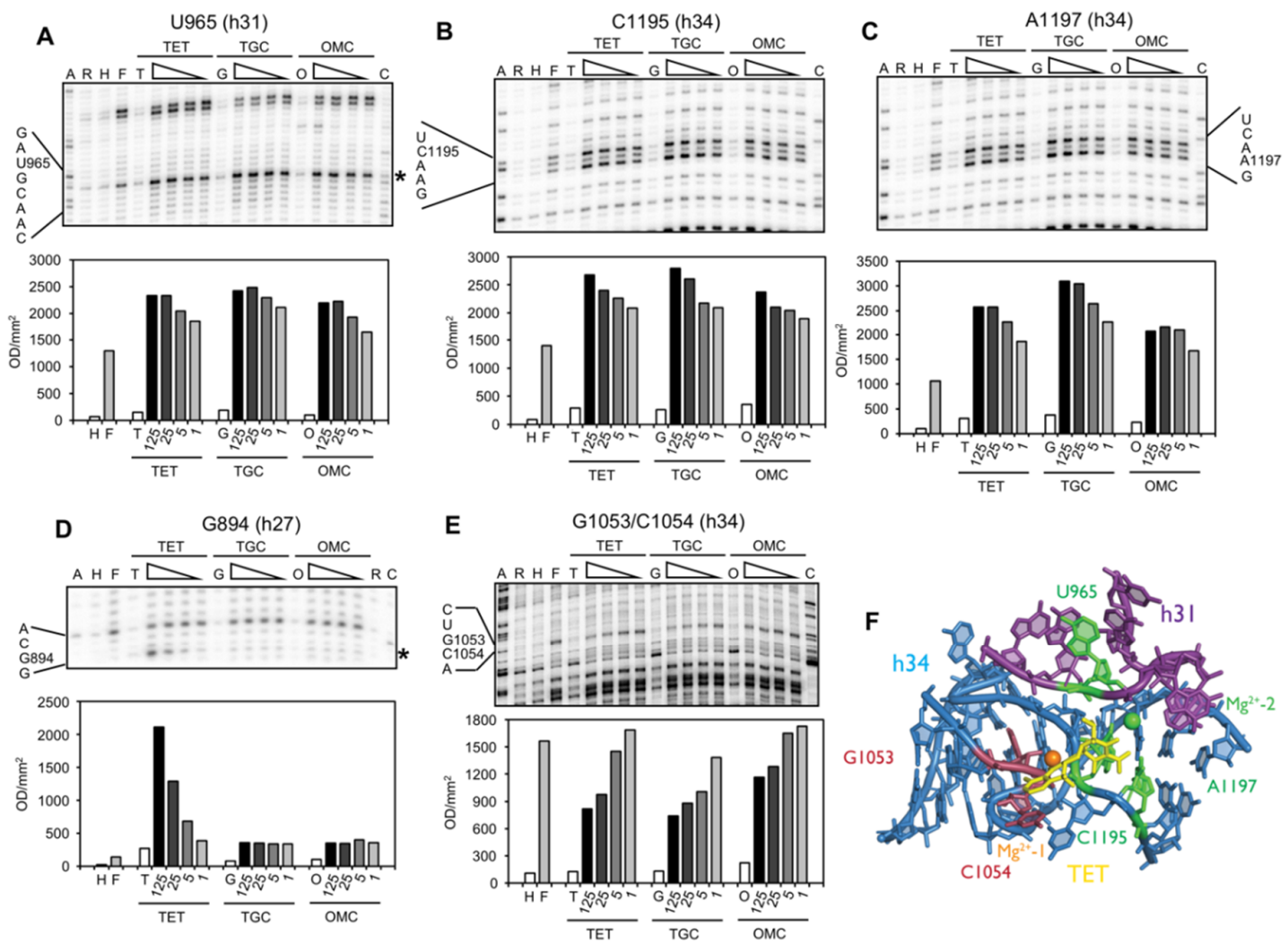

Figure 3. $\mathrm{Fe}^{2+}$-complexed with TET, TGC or OMC affects cleavage of bases in the 16S rRNA. Empty E. coli $70 \mathrm{~S}$ ribosomes $(2 \mu \mathrm{M})$ were incubated with increasing amounts of $\mathrm{Fe}^{2+}$-complexed TET, TGC or OMC $(1-125 \mu \mathrm{M})$ and incubated with sodium ascorbate and hydrogen peroxide. Sites of cleavage were detected by primer extension and analyzed by electrophoresis on denaturing $6 \%$ polyacrylamide gels, sections of which are shown above the plots of their respective quantification. Dose-dependent changes in cleavage intensity were found at nucleotides (A) U965, (B) C1195, (C) A1197, (D) G894, and (E) G1053/C1054. The dideoxy sequencing lanes are indicated with A and C; the unmodified RNA with $\mathrm{R} ; \mathrm{Fe}^{2+}$ incubated rRNA in the absence of sodium ascorbate and hydrogen peroxide with $\mathrm{H}$; Fenton-cleaved rRNA in the absence of antibiotics with F; unmodified rRNA in the presence of $125 \mu \mathrm{M}$ antibiotic; TET, TGC, OMC with T, G, and O, respectively; Fenton-cleaved rRNA in the presence of the respective antibiotic under the TET, TGC, and OMC headers where the wedge represents the presence of $125,25,5$, and $1 \mu \mathrm{M}$ of the respective antibiotic. The extent of rRNA cleavage in the presence of increasing amounts of antibiotic was quantified in a phosphorimager and is shown below the gel sections with a comparison to the control Fenton-cleaved rRNA in the absence of antibiotic (shown in lanes designated " $\mathrm{F}^{\prime}$ ). Quantification was adjusted for loading differences by normalization to regions unaffected by TET, TGC or OMC. Note an identical gel slice is shown in panels B and C as the specified nucleotides are close in primary sequence. (F) Sites of increased (green: U965, C1195, and A1197) and decreased (red C1053, C1054) Fenton cleavage in the presence of the respective antibiotic within the primary tetracycline binding site [4] are shown. The $16 \mathrm{~S}$ rRNA helices, h31 and h34, are colored purple and blue, respectively while the $\mathrm{Mg}^{2+}$ coordinated by tetracycline rings $\mathrm{B}$ and $\mathrm{C}$ is colored orange and the $\mathrm{Mg}^{2+}$ coordinated near tetracycline ring A is colored green. RNA residues are numbered according to the E. coli sequence. 
Table 2. $\mathrm{Fe}^{2+}$-mediated and TET-, TGC- or OMC-directed cleavage sites on the 16S rRNA and the corresponding biochemical crystallography and genetic data.

\begin{tabular}{|c|c|c|c|}
\hline $\begin{array}{l}\mathrm{Fe}^{2+} \text { Cleavage } \\
\text { Sites }^{\text {a }}\end{array}$ & $\begin{array}{c}\text { Specificl } \\
\text { Non-Specific } \\
\end{array}$ & TET-/TGC-Site ${ }^{c}$ & Biochemical and Genetic Data ${ }^{a}$ \\
\hline G242-G247 (h11) & ns $(\mathrm{T})$ & site-2/site-5 & $\begin{array}{l}\text { protection against methylation by DMS at A892 (TET) [25] and } \\
\text { A909 (tRNA) [34]; TET-inhibited crosslink U244 × G894 [35] }\end{array}$ \\
\hline A279 (h11) & ns $(\mathrm{T})$ & site-2/site-5 & $\begin{array}{l}\text { protection against methylation by DMS at A892 (TET) [25] and } \\
\text { A909 (tRNA) [34]; TET-inhibited crosslink U244 } \times \text { G894 [35] }\end{array}$ \\
\hline A412/G413 (h16) & ns (TGO) & & \\
\hline U421/C422 (h16) & ns (TGO) & & \\
\hline G505/G506 (h18) & ns (TG) & & \\
\hline U531/A532 & ns (TG) & & protection against methylation by DMS at G529-G532 (tRNA) [34] \\
\hline G682/G683 (h23) & ns (T) & & protection against methylation by DMS at G693 (tRNA) [34] \\
\hline U692/G693 (h23) & ns (TG) & & protection against methylation by DMS at G693 (tRNA) [34] \\
\hline A702/G703 (h23) & ns (TG) & & protection against methylation by DMS at G693 (tRNA) [34] \\
\hline U788/U789 (h24) & ns (TGO) & & $\begin{array}{l}\text { protection against methylation by DMS at } \\
\text { A790/G791/A794/C795 (tRNA) [34] }\end{array}$ \\
\hline G894 (h27) & $\mathrm{s}(\mathrm{T})$ & site-2/site- 5 & $\begin{array}{l}\text { protection against methylation by DMS at A892 (TET) [25] and } \\
\text { A909 (tRNA) [34]; TET-inhibited crosslink U244 } \times \text { G894 [35] }\end{array}$ \\
\hline G925-C930 (h28) & ns (TGO) & & protection against methylation by DMS at G928 (tRNA) [34] \\
\hline $\begin{array}{l}\text { U957/A958 } \\
\text { (h30/h31) }\end{array}$ & ns $(\mathrm{O})$ & & $\begin{array}{l}\text { enhanced methylation by DMS at G954 and A977-C980, } \\
\text { protection against methylation by DMS at A983 (S7) [36] }\end{array}$ \\
\hline U965 (h31) & $\mathrm{s}(\mathrm{TGO})$ & site-1 & $\begin{array}{c}\text { inhibition of crosslink A967 } \times \text { C1400 [35]; A965U/G966U/A967C } \\
\text { mutation: TET resistance in H. pylori [37] }\end{array}$ \\
\hline G1053/C1054 (h34) & $\mathrm{s}(\mathrm{TGO})$ & site-1 & $\begin{array}{c}\text { enhanced methylation by DMS at C1054 (TET, TGC) [15,25]; } \\
\text { G1058C mutation: TET resistance in P. acnes [20] and } \\
\text { B. hyodysenteriae [22] }\end{array}$ \\
\hline G1166-A1169 (h40) & ns (T) & site-3 & \\
\hline C1195/A1197 (h34) & s (TGO) & site-1 & $\begin{array}{c}\text { enhanced methylation by DMS at C1054 (TET, TGC) [15,25]; } \\
\text { G1058C mutation: TET resistance in P. acnes [20] and } \\
\text { B. hyodysenteriae [22] }\end{array}$ \\
\hline A1257 (h41) & ns $(G)$ & & protection against methylation by DMS at A1256 (S7) [36] \\
\hline G1260 (h41) & ns $(G)$ & & enhanced methylation by DMS at A1261 (S7 + S9) [36] \\
\hline A1360 (h43) & ns (G) & & protection against methylation by DMS at A1360 (S7) [36] \\
\hline
\end{tabular}

\section{Discussion}

Omadacycline is a promising aminomethylcycline with therapeutic potential against severe infectious diseases. An in-depth mechanistic analysis is warranted, because resistance to first and second generation tetracyclines is already widespread $[8,10]$, and resistance to TGC is being observed [38-42]. Structurally, OMC is more similar to TGC than to TET, since the former two are both derived from minocycline and carry a modification, albeit a different one, at the $\mathrm{C} 9$ position of the tetracycline D-ring (Figure 1). The OMC MIC values against the E. coli test strains, however, are more similar to TET than to TGC. They correlate nicely with the binding affinities of the respective drugs to E. coli ribosomes, which are also similar for TET and OMC [4,13], but 10-20-fold higher for TGC $[4,17]$. According to the crystal structures showing TGC bound to either Thermus thermophilus $70 \mathrm{~S}$ ribosomes or $30 \mathrm{~S}$ subunits, the tighter binding of TGC at the primary site- 1 is likely to result from additional interactions formed between the 9-t-butylglycylamido substituent and the rRNA (in particular with C1054) [4,5]. Identical interactions would not be likely with the substituent of OMC, and TET completely lacks the C9 extension, which would explain their lower affinities. For example, OMC lacks the peptide bond (thus having inherently higher conformational flexibility) in which the amide nitrogen in TGC is the basis of several potential interactions with C1054 [4,5]. However, the $t$-butylaminomethyl sidechain of OMC also bears an amine nitrogen that, similar to TGC, might be 
protonated (theoretical pKa is 12.4 in OMC and 10.7 in TGC) and participate in a hydrogen bond with C1054 [5].

Despite these differences in binding affinities, all three compounds react identically to the tetracycline-resistance mutations in the $16 \mathrm{~S}$ rRNA $(1058 \mathrm{G} \rightarrow \mathrm{C}$ and $966 \mathrm{G} \rightarrow \mathrm{U}$; Figure 1C) which affect the functionally important primary tetracycline binding site [2-5]. Their MIC levels are increased 4- to 8-fold in the mutant strains (Table 1), reproducing the published data for TET and TGC, done using a different protocol [15]. Binding of the three antibiotics to the primary site must, therefore, be very similar, which is the case for TET and TGC in their crystal structures of the 70S ribosome and the $30 \mathrm{~S}$ ribosomal subunit $[4,5]$. So far, no tetracycline derivative has been identified which mediates resistance against these mutations. This is not astonishing, since the contacts between TET or TGC and the primary site all involve interactions of the minimum tetracycline pharmacophore with the invariant sugar-phosphate backbone of the rRNA [7]. Fortunately, the level of resistance these mutations mediate is low and their presence impairs cell growth. In fact, we have been unable to generate a viable E. coli strain which carries both mutations in its 16S rRNA (G. Fleischer, C. Heidrich, C. Berens; unpublished observations).

Binding of all three compounds to the primary site is further supported by chemical probing data. DMS modification at C1054 is enhanced in the presence of all three antibiotics, $\mathrm{Fe}^{2+}$-mediated cleavage is detected at U965 in h31, at G1053, C1054, and at C1195 and A1197 in h34. Cleavage at U965 is most likely due to $\mathrm{Fe}^{2+}$ bound in place of the second $\mathrm{Mg}^{2+}$ (Figure $3 \mathrm{~F}, \mathrm{Mg}^{2+}-2$ ), which was not distinguished in the initial crystal structures [2,3], but was subsequently observed in proximity to bases in $\mathrm{h} 31[4,5]$. This $\mathrm{Mg}^{2+}$ interacts directly with the phosphate group connecting the bases A965 (in T. thermophilus) and G966. Complexation of a second metal ion to the tetracycline A ring has been described, with the $\mathrm{C} 4$ dimethylamino group playing an important role [43]. Cleavage and protection in h34 (G1053 and C1054) is most likely mediated by $\mathrm{Fe}^{2+}$ bound to positions C-11/C-12 of the antibiotics. An equivalent $\mathrm{Mg}^{2+}$ ion in the crystal structures of TET $[2,4]$ and TGC $[4,5]$ interacts with the phosphate group connecting C1054 with A1055 and both phosphate groups flanking U1196 and G1197. The protection alteration in Fenton cleavage in h34 could reflect both a shielding of G1053/C1054 by tetracycline and/or a tetracycline-induced localized distortion that decreases cleavage of G1053/C1054 and enhances cleavage of C1195/A1197 close to the position of a structurally important $\mathrm{Mg}^{2+}$ ion (Figure 1C) that is constitutively present at this position [4].

We also observed TET-dependent cleavage at G894 in helix h27. G894 is part of a secondary TET binding site (site-5: Figure 1B) [2,3], is close to A892, which is protected from methylation by DMS in the presence of TET [25], and is the site of a TET-inhibited crosslink to U244 [35]. This once again demonstrates excellent agreement between the Fenton cleavage data and published biochemical (crosslinks, chemical probing), genetic (resistance mutations) and structural data [2,3] (Figure 4). Fenton cleavage was not observed at this position in the previous study [15], but this might be due to the different experimental conditions used. Unlike TET, TGC and OMC show neither protection from DMS modification, nor Fenton cleavage at these positions. The initial enhancement seen at low concentrations of antibiotics might be due to indirect effects caused by drug binding to another site which affects exposure to DMS at A892. Since TGC is also not observed to bind to the secondary site $[4,5]$, the simplest explanation would be that this site is not bound by TGC and OMC and, therefore, it represents a secondary tetracycline-binding site without biological activity. 


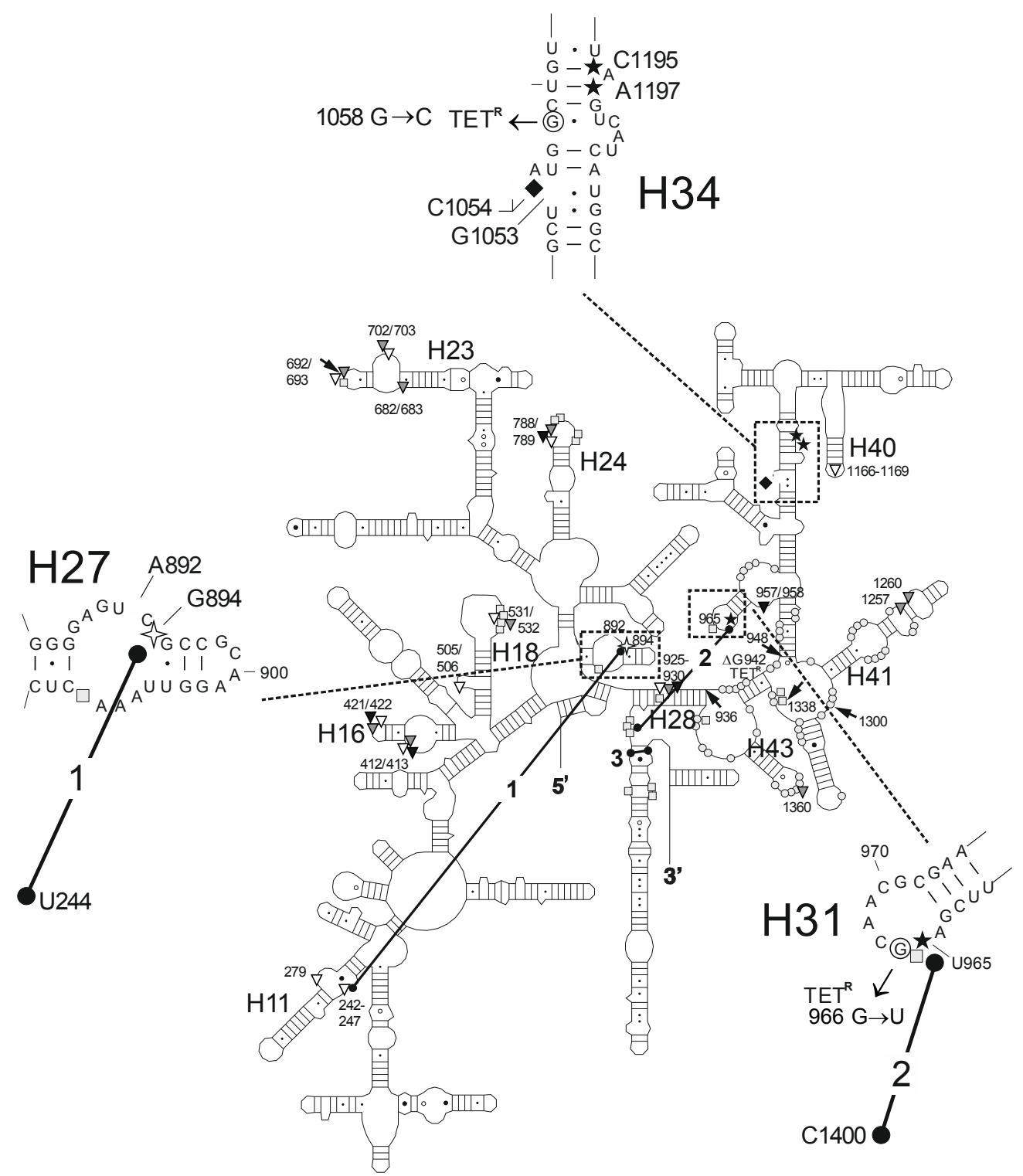

Figure 4. Summary of the interaction sites of TET, TGC, and OMC with the $16 \mathrm{~S}$ rRNA. The secondary structure of the E. coli $16 \mathrm{~S}$ rRNA is shown schematically [44]. Located within the stippled boxes and shown in more detail in the enlarged sections are bases that (i) display altered reactivity towards DMS probing in the presence of TET, TGC or OMC (white diamond: TET only; black diamond: all three) $[15,25]$; (ii) lead to weak resistance against TET, TGC, and OMC when mutated $\left(\mathrm{TET}^{\mathrm{R}}\right.$ ) $[15,20,21,37]$; show either (iii) $\mathrm{Fe}^{2+}$-mediated specific cleavage (white 4-pointed star, black star) [15], or (iv) protection from $\mathrm{Fe}^{2+}$-mediated cleavage in the presence of TET, TGC, and OMC (white 5-pointed star). In addition, the secondary structure contains (i) sites with altered reactivity towards DMS in the presence of tRNA (grey rectangle) [34] or the S7 protein (grey circle) [36]; (ii) direct photocrosslinks to TET (black arrow) [33,45]; (iii) RNA-RNA crosslinks affected by TET (black dumbbell) [35] or (iv) sites with $\mathrm{Fe}^{2+}$-mediated non-specific cleavage in the presence of TET (white triangle), TGC (grey triangle) or OMC (black triangle).

Antibiotic-specific Fenton cleavage sites were not identified in h29 which is close to TET site- 4 and site-6 (Figure 1B) [3]. Biochemical [33,45] and genetic [37] data suggests that tetracycline binds in this area and Fenton cleavage was detected in a previous study at nucleotides 1139-1341 [15]. Possibly, these cleavages are not observed here due to the respective experimental conditions in the two studies. Crystal structures of TET and TGC bound to 70S ribosomes [4] and of TGC bound to 30S ribosomal 
subunits [5] failed to find antibiotic at any of the secondary sites from the earlier 30S ribosomal subunit structures [2,3]. Photocrosslinking also yielded different results using either $70 \mathrm{~S}$ ribosomes or $30 \mathrm{~S}$ ribosome subunits [33,45], with crosslinks to $70 \mathrm{~S}$ ribosomes occurring at TET concentrations of $40 \mu \mathrm{M}$ and higher [33].

We did detect additional cleavage signals (Table 2, Figure S4, also summarized in Figure 4), but only at high concentrations of antibiotic. We attribute this to the different protocol used here, because such cleavage sites had not been observed before [15]. Most of these cleavage sites correlate well with sites of tetracycline binding found in earlier crystal structures [2,3], sites of altered reactivity towards DMS probing in the presence of TET, tRNA or the S7 protein $[25,34,36]$, photo crosslinks involving either rRNA-rRNA [35] or TET-rRNA [33] and mutations leading to TET/TGC resistance $[15,20,21]$ (Figure 4). Only the Fenton cleavages at positions A412/G413 and U421/C422, which were observed for all three antibiotics, and at positions G505/G506, which were observed for TET and TGC, do not correspond to any data from biochemistry, crystallography or genetic studies. The assumption that these signals are non-specific, due to their appearance at only the highest antibiotic concentration $(125 \mu \mathrm{M})$, is supported by the observation that similarly high TET concentrations (i.e., $40-250 \mu \mathrm{M}$ ) were required to give distinct signals in the biochemical studies [25,33,35]. In further agreement with a non-specific nature of these cleavage sites, a mere four of the sixteen signals were obtained with all antibiotics. The remaining cleavage sites were detected for TET, TGC or both. The idiosyncratic nature of these cleavage events most likely reflects small differences in the structural and chemical properties of the three derivatives, due to their different modifications, allowing them to interact with different pockets in the $30 \mathrm{~S}$ ribosomal subunit. In conclusion, OMC interacts with the ribosome like a typical tetracycline. It is susceptible to mutations in the $16 \mathrm{~S}$ rRNA, like all other tetracycline derivatives tested so far.

\section{Materials and Methods}

\subsection{Materials}

All chemicals were either from Sigma or Roth. Tetracycline-hydrochloride (\#T7660) was from Sigma-Aldrich, tigecycline was from Pfizer (New York City, NY, USA), and omadacycline was supplied by Paratek Pharmaceuticals (Boston, MA, USA). Plasmid DNA was isolated using NucleoSpin Plasmid kits (Macherey \& Nagel). DNA oligonucleotide primers were from Eurofins Genomics and $\left[\gamma^{-}{ }^{32} \mathrm{P}\right]-\mathrm{ATP}$ was from PerkinElmer.

\subsection{Strains and Plasmids}

E. coli DH5 $\alpha$ (CGSC \#12384; [46]) was routinely used as plasmid host. E. coli CAN/20-E12 $(r b n, r n a, r n b, r n d)[47,48]$ served as source for the 70S ribosomes. E. coli ATCC-25922 (ATCC \#25922) was the quality control strain for the MIC determinations. E. coli TA527 $\left(\mathrm{F}^{-}\right.$, ara, $\Delta l a c$, thi, $\Delta r r n E$, $\Delta\left(\right.$ rrsB-gltT-rrlB)101, $\Delta\left(\right.$ rrsH-ileV-alaV-rrlH)103, $\Delta\left(\right.$ rrsG-gltW-rrlG)30::lacZ $Z^{+}, \Delta($ rrsA-ileT-alaT-rrlA $) 34$, $\Delta\left(r r s D\right.$-ileU-alaU-rrlD)25:: cat $^{+}, \Delta\left(r r s C\right.$-gltU-rrlC)15:: cat $^{+}$ilv $\left.^{+}\right)$(CGSC \#12282; [26]) was used to measure MIC values for TET, TGC, and OMC of mutated $16 \mathrm{~S}$ rRNA in the absence of a wild type background. This strain is deleted for all seven operons encoding rDNA genes. For viability, E. coli TA527 therefore contains the pSC101 derivative $\mathrm{pHK}-\mathrm{rrnC}^{+}$bearing the entire $\mathrm{rrnC}$ operon from $E$. coli. The plasmid pKK3535, a pBR322 derivative which carries the 7.5-kb BamHI fragment from $\lambda$ rif $^{\mathrm{d}}$ containing the entire $r r n B$ operon from E. coli, was taken as a wild type rRNA control [27]. The plasmid pKK1058C is a pKK3535 derivative bearing a point mutation of $\mathrm{G} \rightarrow \mathrm{C}$ at base 1058 of the $16 \mathrm{~S}$ rRNA [20]. The plasmid pKK966U is a pKK3535 derivative bearing a point mutation of $\mathrm{G} \rightarrow \mathrm{U}$ at base 966 of the 16S rRNA [15]. The rRNA residues were numbered according to the E. coli scheme and helices indicated using the standard nomenclature throughout this manuscript [49]. Chemically-competent TA527/pHK-rrnC are transformed with either pKK3535 or one of its mutant derivatives. Transformants that grow on ampicillin (pKK3535) are checked for loss of kanamycin resistance indicating the loss of pHK-rrnC. 
This ensures a clean, homogenous genetic background for the rRNA to check the consequences of individual mutations in the rRNAs.

\subsection{MIC Determinations}

Antibiotic susceptibility testing was performed via the agar dilution MIC methodology, using Mueller Hinton Agar and following the recommendations of the Clinical and Laboratory Standards Institute (CLSI) as set out in documents M7-A8 and M100-S21, except that bacterial colony growth was evaluated after $40-44 \mathrm{~h}$ at $35^{\circ} \mathrm{C}$, due to the slower growth of the TA527 test strains. The longer incubation time did not affect the MIC values of the quality control strain ATCC-25922, which fall nicely into the permitted range of concentrations from Table 4A of the CLSI document M100-S21 (see Table 1). To prepare the inoculum, strains were grown to a $0.5 \mathrm{McFarland}$ standard, which was determined by measuring the optical density at $625 \mathrm{~nm}$. Ampicillin $(100 \mu \mathrm{g} / \mathrm{mL})$ for selection of the pKK3535-plasmids in the TA527 strain was added to the growth medium.

\subsection{Isolation of $70 S$ Ribosomes}

Isolation of $70 \mathrm{~S}$ ribosomes followed the protocol described previously [50] with modifications to scale the initial fermentation to $100 \mathrm{~L}$, which yielded $89 \mathrm{~g}$ of $E$. coli CAN/20-E12. This cell pellet was suspended in $3 \mathrm{~mL}$ TICO buffer (10 mM HEPES-KOH, pH 7.6; $6 \mathrm{mM} \mathrm{MgCl}_{2} ; 30 \mathrm{mM} \mathrm{NH}_{4} \mathrm{CI}$; $6 \mathrm{mM} \beta$-mercaptoethanol) supplemented with $0.25 \mathrm{mM}$ phenylmethanesulfonyl fluoride per $1 \mathrm{~g}$ of cells. The cell suspension was French-pressed and the lysate cleared with two centrifugation steps; the first for $45 \mathrm{~min}$ at 30,000 $\times \mathrm{g}$ and the second for $17 \mathrm{~h}$ at 72,500 $\times \mathrm{g}$. The pellet (crude ribosomes) from the second centrifugation step was resuspended in TICO buffer. A fraction containing $4000 \mathrm{~A}_{260}$ units of these crude ribosomes was loaded to a $5.7 \%-40 \%$ sucrose gradient (in TICO buffer), prepared in a $15 \mathrm{Ti}$ Zonal rotor and centrifuged $17 \mathrm{~h}$ at 23,000 rpm. The gradient was fractioned and the fractions containing 70S particles were pooled, centrifuged at $85,000 \times \mathrm{g}$ for $22 \mathrm{~h}$ and the washed pellet resuspended in TICO buffer at $600 \mathrm{~A}_{260} / \mathrm{mL}$.

\subsection{Chemical Modification of $70 S$ Ribosomes with DMS}

An amount of $25-30$ pmol of 70 S ribosomes in $48 \mu \mathrm{L}$ TAKA 7 buffer $(50 \mathrm{mM}$ Tris-HCl, $\mathrm{pH} 7.5$; $70 \mathrm{mM} \mathrm{NH}_{4} \mathrm{Cl} ; 30 \mathrm{mM} \mathrm{KCl} ; 7 \mathrm{mM} \mathrm{MgCl}_{2}$ ) were incubated at $37^{\circ} \mathrm{C}$ for $20 \mathrm{~min}$, followed by incubation at ambient temperature for $5 \mathrm{~min}$ in the absence or presence of the respective antibiotic (final volume $49 \mu \mathrm{L}$ ). The dimethylsulfate (DMS) reaction was started by adding $1 \mu \mathrm{L}$ DMS (1:10 dilution in 96\% ethanol) and incubated at room temperature for $6 \mathrm{~min}$. The reaction was stopped with $2 \mu \mathrm{L}$ of $\beta$-mercaptoethanol (diluted 1:5 in water). The sample was precipitated by adding $2 \mu \mathrm{L}$ glycogen $(10 \mathrm{mg} / \mathrm{mL})$ and $300 \mu \mathrm{L}$ of a mixture of ethanol $/ 0.3 \mathrm{M}$ sodium acetate, $\mathrm{pH} 5$.

\subsection{Fenton-Mediated Hydroxyl Radical Cleavage Reactions}

$\mathrm{Fe}^{2+}$-mediated hydroxyl radical cleavage reactions were carried out as described previously [51]. An amount of $4 \mu \mathrm{L}$ of ribosomes ( 5 pmol per $\mu \mathrm{L}$ diluted in TAKA $), 1 \mu \mathrm{L}$ of either a $10 \times$ antibiotic stock solution or $\mathrm{H}_{2} \mathrm{O}$, and $2 \mu \mathrm{L}$ of $5 \times \mathrm{NCB}\left(125 \mathrm{mM}\right.$ MOPS-KOH, pH 7.0; $15 \mathrm{mM} \mathrm{MgCl}_{2} ; 0.5 \mathrm{mM}$ spermidine) were incubated for $30 \mathrm{~min}$ at $37 \pm 2{ }^{\circ} \mathrm{C}$, followed by a $10 \mathrm{~min}$ incubation at room temperature. Then $1 \mu \mathrm{L}$ of $2.5 \mathrm{mM} \mathrm{FeCl}_{2}$ was added to the reaction tube, mixed by centrifugation in a picofuge and incubated for $1 \mathrm{~min}$ before adding $1 \mu \mathrm{L}$ of $12.5 \mathrm{mM}$ sodium ascorbate. After $1 \mathrm{~min}$ incubation, $1 \mu \mathrm{L}$ of $12.5 \mathrm{mM} \mathrm{H}_{2} \mathrm{O}_{2}$ was added and rapidly mixed to initiate the reaction. The final concentrations were $250 \mu \mathrm{M}$ for $\mathrm{Fe}^{2+}$ and $1.25 \mathrm{mM}$ for both sodium ascorbate and $\mathrm{H}_{2} \mathrm{O}_{2}$. Instead of $\mathrm{FeCl}_{2}, 1 \mu \mathrm{L} \mathrm{H} \mathrm{H}_{2} \mathrm{O}$ were added to the control sample. In the $\mathrm{Mg}^{2+}$ competition experiments, $\mathrm{MgCl}_{2}$ was added as a $10 \times$ stock solution of the final $\mathrm{Mg}^{2+}$ concentration to the $1.25 \mathrm{mM} \mathrm{FeCl}_{2}$ solution. This mixture was then pipetted into the reaction tube and the cleavage reaction continued as above. The cleavage reaction was stopped after $1 \mathrm{~min}$ by adding thiourea to a final concentration of $125 \mathrm{mM}$. 
For precipitation, the sample volume was first increased to $100 \mu \mathrm{L}$ with $\mathrm{H}_{2} \mathrm{O}$. Then, $2 \mu \mathrm{L}$ of a $10 \mathrm{mg} / \mathrm{mL}$ glycogen solution and $300 \mu \mathrm{L}$ ethanol/0.3 M sodium acetate, $\mathrm{pH}$ 5, were added.

\subsection{Extraction of $r R N A$}

The rRNA was isolated as described [31]. The ethanol-precipitated pellets were resuspended in $200 \mu \mathrm{L}$ RE-buffer (300 mM sodium-acetate; $0.5 \%(w / v)$ sodium dodecyl sulfate (SDS); $5 \mathrm{mM}$ EDTA), supplemented with 8 Units RNAse Inhibitor ( $40 \mathrm{U} / \mu \mathrm{L}$; Roche) and stored at $4{ }^{\circ} \mathrm{C}$ until use. Precipitated SDS was dissolved by gentle shaking at ambient temperature for $10 \mathrm{~min}$. The ribosomal proteins were removed by successive phenol, phenol-chloroform-isoamylalcohol (25:24:1) and chloroform-isoamylalcohol (24:1) extractions. After a final centrifugation step at 15,000 $\times \mathrm{g}$ for $5 \mathrm{~min}$, the RNA-containing solution $(200 \mu \mathrm{L})$ was transferred to a new reaction tube and precipitated by adding $2 \mu \mathrm{L}$ of glycogen $(10 \mathrm{mg} / \mathrm{mL})$ and $600 \mu \mathrm{L}$ of a mixture of ethanol/0.3 M sodium acetate, $\mathrm{pH} 5$. The rRNA was resuspended in $30 \mu \mathrm{L}$ of DEPC-treated water and stored at $-78^{\circ} \mathrm{C}$.

\subsection{Primer Extension Reaction}

The primer extension reaction was performed as described [31]. Briefly, $2 \mu \mathrm{L}$ of the isolated rRNA $(0.5-0.7 \mu \mathrm{g} / \mu \mathrm{L})$ was mixed with $1 \mu \mathrm{L} 5 \times$ Q-solution (Qiagen, One-step RT-PCR Kit) and $1 \mu \mathrm{L}$ $5^{\prime}-\left[{ }^{32} \mathrm{P}\right]$-labelled primer. The primers used were spaced approximately every 150 nucleotides on the $16 \mathrm{~S}$ rRNA [52]. For better mapping of some of the cleavage sites, we used the following primers: 563rev (CGTGCGCTTTACGCCCAG), 704rev (CGGTATTCCTCCAGATCT), 938rev (ACCACAT GCTCCACCGC), 1098rev (GGGTTGCGCTCGTTGCG), and 1256rev (TTGCTCTCGCGAGGTCGCT) instead of the primers \#683, \#906, \#1199, and \#1508 [52]. The hybridization was carried out by heating the mixture for $1 \mathrm{~min}$ at $94{ }^{\circ} \mathrm{C}$ followed by continuous cooling to $50{ }^{\circ} \mathrm{C}$. The extension reaction was started by adding $10.5 \mu \mathrm{L}$ extension-mix ( $2 \mu \mathrm{L} 2.5 \mathrm{mM}$ dNTPs; $3 \mu \mathrm{L} 5 \times$ first strand buffer (Invitrogen); $1.5 \mu \mathrm{L} 5 \times$ Q-solution; $1 \mu \mathrm{L}$ 0.1 M DTT; $0.2 \mu \mathrm{L}$ RNAse inhibitor (Promega); $0.2 \mu \mathrm{L}$ SuperScriptIII reverse transcriptase (200 U/ $\mu \mathrm{L}$; Invitrogen); $2.6 \mu \mathrm{L}$ DEPC-treated $\mathrm{H}_{2} \mathrm{O}$ ) to $4.5 \mu \mathrm{L}$ of the hybridization sample. The extension reaction was carried out in a final volume of $15 \mu \mathrm{L}$ for $50-60 \mathrm{~min}$ at $50{ }^{\circ} \mathrm{C}$. To stop the reaction, the RNA was degraded by adding $4 \mu \mathrm{L} 1 \mathrm{M} \mathrm{NaOH}$, followed by 30-60 min incubation at $42{ }^{\circ} \mathrm{C}$. After neutralization by adding $4 \mu \mathrm{L}$ of $1 \mathrm{M} \mathrm{HCl}$, the cDNA was precipitated by the addition of $2 \mu \mathrm{L}$ EDTA $(0.5 \mathrm{M}, \mathrm{pH} 8), 2 \mu \mathrm{L}$ glycogen $(10 \mathrm{mg} / \mathrm{mL})$, and $100 \mu \mathrm{L}$ ethanol $/ 0.3 \mathrm{M}$ sodium acetate, $\mathrm{pH} 5$. The samples were precipitated at $-20^{\circ} \mathrm{C}$ for $3-6 \mathrm{~h}$ or overnight. Following precipitation, the cDNA was washed with $80 \mu \mathrm{L} \mathrm{70 \%} \mathrm{ethanol,} \mathrm{the} \mathrm{ethanol} \mathrm{removed} \mathrm{with} \mathrm{a} \mathrm{pipette} \mathrm{and} \mathrm{the} \mathrm{pellet} \mathrm{resuspended}$ in $10 \mu \mathrm{L}$ loading buffer (0.3\% each of bromophenol-blue and xylene cyanol, $10 \mathrm{mM}$ EDTA, pH 7.5, and $97.5 \%$ deionized formamide).

Supplementary Materials: The following are available online at www.mdpi.com/2079-6382/5/4/32/s1, Figure S1: $\mathrm{Fe}^{2+}$-complexed with TET, TGC or OMC affects cleavage of bases in 16S rRNA, Figure S2: $\mathrm{Mg}^{2+}$ competes with $\mathrm{Fe}^{2+}$-mediated cleavage, Figure S3: $\mathrm{Fe}^{2+}$-complexed with TET, TGC or OMC cleaves bases in $16 \mathrm{~S}$ rRNA non-specifically.

Acknowledgments: We dedicate this manuscript to the memory of Wolfgang Hillen, whose input to the project was invaluable, but who unfortunately passed away before the experimental phase was initiated. We also thank the German Research Foundation DFG for support through project HI 291/12-1 to W.H. and C.B. Additional support was provided by Bizkaia:Talent and the European Union's Seventh Framework Program (Marie Curie Actions; COFUND; to S.C., A.S., and T.K.), a Marie Curie Action Career Integration Grant (PCIG14-GA-2013-632072 to P.F.) and the Ministerio de Economía Y Competitividad (CTQ2014-55907-R to P.F. and S.C.).

Author Contributions: C.G.H., S.M., and C.B. conceived and designed the experiments; C.G.H. and S.M. performed the experiments; C.G.H., S.M., S.C., and C.B. analyzed the data; A.S., S.C., P.F., and J.N.S. contributed reagents/materials/analysis tools; A.S., S.C., P.F., C.G.H., and C.B. wrote the paper.

Conflicts of Interest: This study was funded by Novartis. J.N.S. is an employee of Paratek Pharmaceuticals. Neither company had a role in the design of the study; in the collection, analyses, or interpretation of data; in the writing of the manuscript, and in the decision to publish the results. 


\section{Abbreviations}

The following abbreviations are used in this manuscript:

$\begin{array}{ll}\text { TET } & \text { Tetracycline } \\ \text { TGC } & \text { Tigecycline } \\ \text { OMC } & \text { Omadacycline } \\ \text { aa } & \text { amino acid } \\ \text { tRNA } & \text { transfer RNA } \\ \text { rRNA } & \text { ribosomal RNA } \\ \text { MIC } & \text { minimal inhibitory concentration } \\ \text { CLSI } & \text { Clinical \& Laboratory Standards Institute } \\ \text { DMS } & \text { Dimethyl sulfate } \\ \text { EDTA } & \text { Ethylenediaminetetraacetic acid } \\ \text { DEPC } & \text { Diethyl pyrocarbonate } \\ \text { cDNA } & \text { complementary DNA }\end{array}$

\section{References}

1. Rasmussen, B.; Noller, H.F.; Daubresse, G.; Oliva, B.; Misulovin, Z.; Rothstein, D.M.; Ellestad, G.A.; Gluzman, Y.; Tally, F.P.; Chopra, I. Molecular basis of tetracycline action: Identification of analogs whose primary target is not the bacterial ribosome. Antimicrob. Agents Chemother. 1991, 35, 2306-2311. [CrossRef] [PubMed]

2. Brodersen, D.E.; Clemons, W.M., Jr.; Carter, A.P.; Morgan-Warren, R.J.; Wimberly, B.T.; Ramakrishnan, V. The structural basis for the action of the antibiotics tetracycline, pactamycin, and hygromycin B on the $30 \mathrm{~S}$ ribosomal subunit. Cell 2000, 103, 1143-1154. [CrossRef]

3. Pioletti, M.; Schlünzen, F.; Harms, J.; Zarivach, R.; Glühmann, M.; Avila, H.; Bashan, A.; Bartels, H.; Auerbach, T.; Jacobi, C.; et al. Crystal structures of complexes of the small ribosomal subunit with tetracycline, edeine and IF3. EMBO J. 2001, 20, 1829-1839. [CrossRef] [PubMed]

4. Jenner, L.; Starosta, A.L.; Terry, D.S.; Mikolajka, A.; Filonava, L.; Yusupov, M.; Blanchard, S.C.; Wilson, D.N.; Yusupova, G. Structural basis for potent inhibitory activity of the antibiotic tigecycline during protein synthesis. Proc. Natl. Acad. Sci. USA 2013, 110, 3812-3816. [CrossRef] [PubMed]

5. Schedlbauer, A.; Kaminishi, T.; Ochoa-Lizarralde, B.; Dhimole, N.; Zhou, S.; López-Alonso, J.P.; Connell, S.R.; Fucini, P. Structural characterization of an alternative mode of tigecycline binding to the bacterial ribosome. Antimicrob. Agents Chemother. 2015, 59, 2849-2854. [CrossRef] [PubMed]

6. Blanchard, S.C.; Gonzalez, R.L.; Kim, H.D.; Chu, S.; Puglisi, J.D. tRNA selection and kinetic proofreading in translation. Nat. Struct. Mol. Biol. 2004, 11, 1008-1014. [CrossRef] [PubMed]

7. Nelson, M.L.; Levy, S.B. The history of the tetracyclines. Ann. N. Y. Acad. Sci. 2011, 1241, 17-32. [CrossRef] [PubMed]

8. Chopra, I.; Roberts, M. Tetracycline antibiotics: Mode of action, applications, molecular biology, and epidemiology of bacterial resistance. Microbiol. Mol. Biol. Rev. 2001, 65, 232-260. [CrossRef] [PubMed]

9. Marshall, B.M.; Levy, S.B. Food animals and antimicrobials: Impacts on human health. Clin. Microbiol. Rev. 2011, 24, 718-733. [CrossRef] [PubMed]

10. Thaker, M.; Spanogiannopoulos, P.; Wright, G.D. The tetracycline resistome. Cell Mol. Life Sci. 2010, 67, 419-431. [CrossRef] [PubMed]

11. Petersen, P.J.; Jacobus, N.V.; Weiss, W.J.; Sum, P.E.; Testa, R.T. In vitro and in vivo antibacterial activities of a novel glycylcycline, the 9-t-butylglycylamido derivative of minocycline (GAR-936). Antimicrob. Agents Chemother. 1999, 43, 738-744. [PubMed]

12. Honeyman, L.; Ismail, M.; Nelson, M.L.; Bhatia, B.; Bowser, T.E.; Chen, J.; Mechiche, R.; Ohemeng, K.; Verma, A.K.; Cannon, E.P.; et al. Structure-activity relationship of the aminomethylcyclines and the discovery of omadacycline. Antimicrob. Agents Chemother. 2015, 59, 7044-7053. [CrossRef] [PubMed]

13. Draper, M.P.; Weir, S.; Macone, A.; Donatelli, J.; Trieber, C.A.; Tanaka, S.K.; Levy, S.B. Mechanism of action of the novel aminomethylcycline antibiotic omadacycline. Antimicrob. Agents Chemother. 2014, 58, 1279-1283. [CrossRef] [PubMed]

14. Macone, A.B.; Caruso, B.K.; Leahy, R.G.; Donatelli, J.; Weir, S.; Draper, M.P.; Tanaka, S.K.; Levy, S.B. In vitro and in vivo antibacterial activities of omadacycline, a novel aminomethylcycline. Antimicrob. Agents Chemother. 2014, 58, 1127-1135. [CrossRef] [PubMed] 
15. Bauer, G.; Berens, C.; Projan, S.J.; Hillen, W. Comparison of tetracycline and tigecycline binding to ribosomes mapped by dimethylsulphate and drug-directed $\mathrm{Fe}^{2+}$ cleavage of $16 \mathrm{~S}$ rRNA. J. Antimicrob. Chemother. 2004, 53, 592-599. [CrossRef] [PubMed]

16. Moore, I.F.; Hughes, D.W.; Wright, G.D. Tigecycline is modified by the flavin-dependent monooxygenase TetX. Biochemistry 2005, 44, 11829-11835. [CrossRef] [PubMed]

17. Olson, M.W.; Ruzin, A.; Feyfant, E.; Rush, T.S., 3rd; O'Connell, J.; Bradford, P.A. Functional, biophysical, and structural bases for antibacterial activity of tigecycline. Antimicrob. Agents Chemother. 2006, 50, 2156-2166. [CrossRef] [PubMed]

18. Berens, C. Interactions of tetracyclines with RNA. In Tetracyclines in Biology, Chemistry and Medicine; Nelson, M., Hillen, W., Greenwald, R.A., Eds.; Birkhäuser: Basel, Switzerland, 2002; pp. 177-196.

19. Noel, G.J.; Draper, M.P.; Hait, H.; Tanaka, S.K.; Arbeit, R.D. A randomized, evaluator-blind, phase 2 study comparing the safety and efficacy of omadacycline to those of linezolid for treatment of complicated skin and skin structure infections. Antimicrob. Agents Chemother. 2012, 56, 5650-5654. [CrossRef] [PubMed]

20. Ross, J.I.; Eady, E.A.; Cove, J.H.; Cunliffe, W.J. 16S rRNA mutation associated with tetracycline resistance in a Gram-positive bacterium. Antimicrob. Agents Chemother. 1998, 42, 1702-1705. [PubMed]

21. Nonaka, L.; Connell, S.R.; Taylor, D.E. 16S rRNA mutations that confer tetracycline resistance in Helicobacter pylori decrease drug binding in Escherichia coli ribosomes. J. Bacteriol. 2005, 187, 3708-3712. [CrossRef] [PubMed]

22. Pringle, M.; Fellström, C.; Johansson, K.-E. Decreased susceptibility to doxycycline associated with a $16 \mathrm{~S}$ rRNA gene mutation in Brachyspira hyodysenteriae. Vet. Microbiol. 2007, 123, 245-248. [CrossRef] [PubMed]

23. Dégrange, S.; Renaudin, H.; Charron, A.; Pereyre, S.; Bébéar, C.; Bébéar, C.M. Reduced susceptibility to tetracyclines is associated in vitro with the presence of $16 \mathrm{~S}$ rRNA mutations in Mycoplasma hominis and Mycoplasma pneumoniae. J. Antimicrob. Chemother. 2008, 61, 1390-1392. [CrossRef] [PubMed]

24. Amram, E.; Mikula, I.; Schnee, C.; Ayling, R.D.; Nicholas, R.A.; Rosales, R.S.; Harrus, S.; Lysnyansky, I. $16 \mathrm{~S}$ rRNA gene mutations associated with decreased susceptibility to tetracycline in Mycoplasma bovis. Antimicrob. Agents Chemother. 2015, 59, 796-802. [CrossRef] [PubMed]

25. Moazed, D.; Noller, H.F. Interaction of antibiotics with functional sites in 16 S ribosomal RNA. Nature 1987, 327, 389-394. [CrossRef] [PubMed]

26. Asai, T.; Zaporojets, D.; Squires, C.; Squires, C.L. An Escherichia coli strain with all chromosomal rRNA operons inactivated: Complete exchange of rRNA genes between bacteria. Proc. Natl. Acad. Sci. USA 1999, 96, 1971-1976. [CrossRef] [PubMed]

27. Brosius, J.; Ullrich, A.; Raker, M.A.; Gray, A.; Dull, T.J.; Gutell, R.R.; Noller, H.F. Construction and fine mapping of recombinant plasmids containing the $r m B$ ribosomal RNA operon of E. coli. Plasmid 1981, 6, 112-118. [CrossRef]

28. Palm, G.J.; Lederer, T.; Orth, P.; Saenger, W.; Takahashi, M.; Hillen, W.; Hinrichs, W. Specific binding of divalent metal ions to tetracycline and to the Tet repressor/tetracycline complex. J. Biol. Inorg. Chem. 2008, 13, 1097-1110. [CrossRef] [PubMed]

29. Ettner, N.; Metzger, J.W.; Lederer, T.; Hulmes, J.D.; Kisker, C.; Hinrichs, W.; Ellestad, G.A.; Hillen, W. Proximity mapping of the Tet repressor-tetracycline- $\mathrm{Fe}^{2+}$ complex by hydrogen peroxide mediated protein cleavage. Biochemistry 1995, 34, 22-31. [CrossRef] [PubMed]

30. McMurry, L.M.; Aldema-Ramos, M.L.; Levy, S.B. Fe ${ }^{2+}$-tetracycline-mediated cleavage of the Tn10 tetracycline efflux protein TetA reveals a substrate binding site near glutamine 225 in transmembrane helix 7. J. Bacteriol. 2002, 184, 5113-5120. [CrossRef] [PubMed]

31. Heidrich, C.G.; Berens, C. Probing RNA structure and ligand binding sites on RNA by Fenton cleavage. In Handbook of RNA Biochemistry, 2nd ed.; Westhof, E., Bindereif, A., Schön, A., Hartmann, R.K., Eds.; WILEY-VCH: Weinheim, Germany, 2014; pp. 301-318.

32. Hertweck, M.; Hiller, R.; Mueller, M.W. Inhibition of nuclear pre-mRNA splicing by antibiotics in vitro. Eur. J. Biochem. 2002, 269, 175-183. [CrossRef] [PubMed]

33. Oehler, R.; Polacek, N.; Steiner, G.; Barta, A. Interaction of tetracycline with RNA: Photoincorporation into ribosomal RNA of Escherichia coli. Nucleic Acids Res. 1997, 25, 1219-1224. [CrossRef] [PubMed]

34. Moazed, D.; Noller, H.F. Transfer RNA shields specific nucleotides in $16 \mathrm{~S}$ ribosomal RNA from attack by chemical probes. Cell 1986, 47, 985-994. [CrossRef] 
35. Noah, J.W.; Dolan, M.A.; Babin, P.; Wollenzien, P. Effects of tetracycline and spectinomycin on the tertiary structure of ribosomal RNA in the Escherichia coli 30S ribosomal subunit. J. Biol. Chem. 1999, 274, 16576-16581. [CrossRef] [PubMed]

36. Powers, T.; Changchien, L.-M.; Craven, G.R.; Noller, H.F. Probing the assembly of the 3' major domain of 16 S ribosomal RNA. Quaternary interactions involving ribosomal proteins S7, S9 and S19. J. Mol. Biol. 1988, 200, 309-319. [CrossRef]

37. Trieber, C.A.; Taylor, D.E. Mutations in the 16S rRNA genes of Helicobacter pylori mediate resistance to tetracycline. J. Bacteriol. 2002, 184, 2131-2140. [CrossRef] [PubMed]

38. Tuckman, M.; Petersen, P.J.; Projan, S.J. Mutations in the interdomain loop region of the tet $A(\mathrm{~A})$ tetracycline resistance gene increase efflux of minocycline and glycylcyclines. Microb. Drug Resist. 2000, 6, 277-282. [CrossRef] [PubMed]

39. Peleg, A.Y.; Adams, J.; Paterson, D.L. Tigecycline efflux as a mechanism for nonsusceptibility in Acinetobacter baumannii. Antimicrob. Agents Chemother. 2007, 51, 2065-2069. [CrossRef] [PubMed]

40. Akiyama, T.; Presedo, J.; Khan, A.A. The tet $A$ gene decreases tigecycline sensitivity of Salmonella enterica isolates. Int. J. Antimicrob. Agents 2013, 42, 133-140. [CrossRef] [PubMed]

41. Deng, M.; Zhu, M.-H.; Li, J.-J.; Bi, S.; Sheng, Z.-K.; Hu, F.-S.; Zhang, J.-J.; Chen, W.; Xue, X.-W.; Sheng, J.-F.; et al. Molecular epidemiology and mechanisms of tigecycline resistance in clinical isolates of Acinetobacter baumannii from a chinese university hospital. Antimicrob. Agents Chemother. 2014, 58, 297-303. [CrossRef] [PubMed]

42. Villa, L.; Feudi, C.; Fortini, D.; García-Fernández, A.; Carattoli, A. Genomics of KPC-producing Klebsiella pneumoniae sequence type 512 clone highlights the role of RamR and ribosomal S10 protein mutations in conferring tigecycline resistance. Antimicrob. Agents Chemother. 2014, 58, 1707-1712. [CrossRef] [PubMed]

43. Lambs, L.; Venturini, M.; Decock-Le Révérend, B.; Kozlowski, H.; Berthon, G. Metal ion-tetracycline interactions in biological fluids. Part 8. Potentiometric and spectroscopic studies on the formation of $\mathrm{Ca}(\mathrm{II})$ and $\mathrm{Mg}(\mathrm{II})$ complexes with 4-dedimethylamino-tetracycline and 6-desoxy-6-demethyl-tetracycline. J. Inorg. Biochem. 1988, 33, 193-210. [CrossRef]

44. Gutell, R.R. Collection of small subunit (16S- and 16S-like) ribosomal RNA structures: 1994. Nucleic Acids Res. 1994, 22, 3502-3507. [CrossRef] [PubMed]

45. Anokhina, M.M.; Barta, A.; Nierhaus, K.H.; Spiridonova, V.A.; Kopylov, A.M. Mapping of the second tetracycline binding site on the ribosomal small subunit of E. coli. Nucleic Acids Res. 2004, 32, 2594-2597. [CrossRef] [PubMed]

46. Hanahan, D. DH5 $\alpha$ competent cells. Focus 1986, 8, 9.

47. Deutscher, M.P.; Marlor, C.W.; Zaniewski, R. Ribonuclease T: New exoribonuclease possibly involved in end-turnover of tRNA. Proc. Natl. Acad. Sci. USA 1984, 81, 4290-4293. [CrossRef] [PubMed]

48. Cheng, Z.F.; Zuo, Y.; Li, Z.; Rudd, K.E.; Deutscher, M.P. The vacb gene required for virulence in Shigella flexneri and Escherichia coli encodes the exoribonuclease RNase R. J. Biol. Chem. 1998, 273, 14077-14080. [CrossRef] [PubMed]

49. Brodersen, D.E.; Clemons, W.M., Jr.; Carter, A.P.; Wimberly, B.T.; Ramakrishnan, V. Crystal structure of the $30 \mathrm{~S}$ ribosomal subunit from Thermus thermophilus: Structure of the proteins and their interactions with $16 \mathrm{~S}$ RNA. J. Mol. Biol. 2002, 316, 725-768. [CrossRef] [PubMed]

50. Blaha, G.; Stelzl, U.; Spahn, C.M.; Agrawal, R.K.; Frank, J.; Nierhaus, K.-H. Preparation of functional ribosomal complexes and effect of buffer conditions on tRNA positions observed by cryoelectron microscopy. Methods Enzymol. 2000, 317, 292-309. [PubMed]

51. Berens, C.; Streicher, B.; Schroeder, R.; Hillen, W. Visualizing metal-ion-binding sites in group I introns by iron(II)-mediated Fenton reactions. Chem. Biol. 1998, 5, 163-175. [CrossRef]

52. Moazed, D.; Stern, S.; Noller, H.F. Rapid chemical probing of conformation in 16S ribosomal RNA and $30 S$ ribosomal subunits using primer extension. J. Mol. Biol. 1986, 187, 399-416. [CrossRef]

(C) 2016 by the authors; licensee MDPI, Basel, Switzerland. This article is an open access article distributed under the terms and conditions of the Creative Commons Attribution (CC-BY) license (http://creativecommons.org/licenses/by/4.0/). 